\title{
Effects of unfractionated heparin and rivaroxaban on the expression of heparanase and fibroblast growth factor 2 in human osteoblasts
}

\author{
JINGJUN XIA ${ }^{1}$, WEI SHENG ${ }^{2}$, LIUBAO PEI ${ }^{3},{\text { NING } \mathrm{LI}^{4} \text {, ZHIPENG ZHANG }}^{1}$, \\ JIALIANG WANG $^{1}$, JIANING ZU ${ }^{1}$, NANXIANG WANG ${ }^{1}$ and DUANYANG WANG ${ }^{1}$ \\ ${ }^{1}$ Department of Orthopaedics, The Second Affiliated Hospital of Harbin Medical University, Harbin, \\ Heilongjiang 150086; ${ }^{2}$ Department of Neurology, The Second Hospital of Harbin, Harbin, Heilongjiang 150001; \\ ${ }^{3}$ Department of Orthopaedics, Shuangyashan Coal General Hospital, Shuangyashan, Heilongjiang 155100; \\ ${ }^{4}$ Department of Orthopaedics, The Fifth Hospital of Harbin, Harbin, Heilongjiang 150001, P.R. China
}

Received March 23, 2016; Accepted March 13, 2017

DOI: $10.3892 / \mathrm{mmr} .2017 .6570$

\begin{abstract}
Long-term treatment with anticoagulants may contribute to osteoporosis. Although unfractionated heparin and rivaroxaban have adverse effects on bone microstructure and function in adult rats, the underlying mechanism remains to be elucidated. Heparanase (HPSE) and fibroblast growth factor (FGF)2 are important signals in bone formation and fracture healing. Therefore, the present study was designed to investigate the effects of unfractionated heparin and rivaroxaban on the expression of HPSE and FGF2 in human osteoblasts. Human osteoblasts were treated with unfractionated heparin $(0.5-50 \mathrm{IU} / \mathrm{ml})$ or rivaroxaban $(0.13-13 \mu \mathrm{g} / \mathrm{ml})$ for different durations. Plasmids encoding HPSE and FGF2 were transfected into osteoblasts, and cell viability was assessed using MTT assays, with mRNA and protein expression levels determined using reverse transcription-quantitative polymerase chain reaction and western blot analyses, respectively. Osteoblast growth was significantly inhibited by treatment with unfractionated heparin $(50 \mathrm{IU} / \mathrm{ml})$ or rivaroxaban (13 $\mu \mathrm{g} / \mathrm{ml})$. Unfractionated heparin alone significantly inhibited the expression of HPSE and FGF2, whereas rivaroxaban inhibited the expression of FGF2 without affecting that of HPSE. Furthermore, the overexpression of HPSE or FGF2 significantly reversed the inhibitory effects of unfractionated heparin and rivaroxaban on osteoblasts. These findings suggested that HPSE and FGF2 signals were involved in the detrimental role of unfractionated heparin and rivaroxaban in
\end{abstract}

Correspondence to: Dr Jingjun Xia, Department of Orthopaedics, The Second Affiliated Hospital of Harbin Medical University, 246 Xuefu Road, Nangang, Harbin, Heilongjiang 150086, P.R. China E-mail: at12615g@126.com

Key words: unfractionated heparin, rivaroxaban, heparanase, fibroblast growth factor, osteoblast human osteoblasts, providing novel information on the side effects of anticoagulants.

\section{Introduction}

Drug-induced osteoporosis is an important adverse effect in patients with various chronic debilitating diseases requiring drug intervention (1), with drug-induced osteoporosis having a significant effect on patient morbidity and mortality rates (2). Treatment with anticoagulants, including heparin, is associated with osteoporosis (3). Heparin can damage bones by reducing bone formation and increasing bone resorption (4). Another anticoagulant, rivaroxaban $\left(\mathrm{XARELTO}^{\circledR}\right)$, is a novel oral drug and a direct inhibitor of factor Xa with, showing $>10,000$-fold higher selectivity for factor Xa, compared with other serine proteases (5). The effects of rivaroxaban on bone metabolism and fracture repair remain to be fully elucidated. A previous study reported that rivaroxaban did not impair fracture healing in a rat femur fracture model (6). By contrast, other studies have found that long-term treatment with rivaroxaban had negative effects on bone metabolism and microstructure in vitro and in vivo (7-9), although rivaroxaban had fewer adverse effects on bone health, compared with heparin (9). However, the mechanisms underlying the negative effects of unfractionated heparin and rivaroxaban remain to be fully elucidated.

Heparanase (HPSE) is an endoglucuronidase, which degrades heparan sulfate proteoglycans (HSPGs) and releases heparin-binding growth factors, including vascular endothelial growth factor (10). HPSE is expressed in osteoblastic cells (11), stimulating bone formation and fracture repair (12). Fibroblast growth factor (FGF) signaling is key in regulating chondrogenesis, osteogenesis and bone homeostasis (13). The FGF family consists of 22 members, which can be classified into three groups: Canonical, hormone-like and intracellular (14). FGF2 is a member of the FGF polypeptide family, which is expressed in osteoblasts and stored in the extracellular matrix (15). Canonical FGFs, including FGF2, are crucial in bone formation (16). As the effects of heparin and rivaroxaban on HPSE and FGFs remain to be fully elucidated, the present 
study was designed to investigate the effect of heparin and rivaroxaban on the expression of HPSE and FGF2 in human osteoblasts.

\section{Materials and methods}

Osteoblast culture and treatment. The human calvarial osteoblast cell line (4600) was purchased from ScienCell Research Laboratories (Shanghai, China) and characterized by the supplier as positive for alkaline phosphatase and osteocalcin. These cells were routinely cultured in osteoblast growth medium (PromoCell GmbH, Heidelberg, Germany) at $37^{\circ} \mathrm{C}$ in a humidified atmosphere of $95 \% \mathrm{O}_{2}$ and $5 \% \mathrm{CO}_{2}$. The cells were seeded into 6 -well plates at a density of $1 \times 10^{5}$ cells/well for reverse transcription-quantitative polymerase chain reaction (RT-qPCR) and western blot analyses, or were seeded in 96-well plates at a density of $5 \times 10^{4}$ cells/well for cell viability assays. The cells were cultured to $\sim 80 \%$ confluence prior to treatment. The osteoblast cells were treated with 0 (negative control), $0.5,5$ and $50 \mathrm{IU} / \mathrm{ml}$ unfractionated heparin in osteoblast growth medium for 1,3 and 5 days. For rivaroxaban treatment, the cells were treated with rivaroxaban (cat. no. BAY 59-7939) obtained from Bayer AG (Leverkusen, Germany), and dissolved in dimethyl sulfoxide (DMSO; Sigma-Aldrich; Merck Millipore, Darmstadt, Germany) at concentrations of $0.13,1.3$ and $13 \mu \mathrm{g} / \mathrm{ml}$ in growth medium at $37^{\circ} \mathrm{C}$ for 1,3 and 5 days (17); as a negative control, the cells were treated with medium containing equivalent concentrations of DMSO.

Plasmid construction and transfection. Plasmids encoding HPSE and FGF2, and the vector control p-EGFP-N1 were obtained from Zoonbio Biotechnology Co., Ltd. (Nanjing, China), and transfected into osteoblasts using Lipofectamine ${ }^{\circledR} 2000$ reagent (Invitrogen; Thermo Fisher Scientific, Inc., Waltham, MA, USA), as described previously (18). Briefly, the cells $\left(1 \times 10^{6}\right.$ cells/well) were trypsinized and seeded $24 \mathrm{~h}$ prior to transfection. The transfection mixture was dissolved in Opti-MEM serum-free medium (Gibco; Thermo Fisher Scientific, Inc., Waltham, MA, USA) and added to the cells. After $24 \mathrm{~h}$, the medium was replaced with fresh medium with or without unfractionated heparin or rivaroxaban at $37^{\circ} \mathrm{C}$ for 3 days. Protein and RNA were subsequently extracted from the cells.

Cell viability assay. Osteoblast viability was assessed using MTT assays. Briefly, the cells were incubated with $20 \mu \mathrm{l}$ of MTT $(0.5 \mathrm{mg} / \mathrm{ml})$ at $37^{\circ} \mathrm{C}$ for $4 \mathrm{~h}$. The culture medium was then removed, and $200 \mu \mathrm{l}$ of DMSO was added to each well, followed by agitation for $10 \mathrm{~min}$ at room temperature. The absorbance of the wells at $490 \mathrm{~nm}$ was measured using an Infinite M200 microplate reader (Tecan, Salzburg, Austria). The viability of the treated cultures was calculated as a percentage of control cultures, with reported data representative of five independent experiments.

$R N A$ isolation and RT-qPCR analysis. Total RNA was extracted from the osteoblasts using TRIzol reagent (Invitrogen; Thermo Fisher Scientific, Inc.). The concentration was examined by Nanodrop 2000 (Thermo, MA, USA). The reverse-transcription PCR reaction was performed using a reverse transcription kit (Thermo Fisher Scientific, Inc.) programmed to $25^{\circ} \mathrm{C} 10 \mathrm{~min}, 37^{\circ} \mathrm{C} 120 \mathrm{~min}, 85^{\circ} \mathrm{C} 5 \mathrm{~min}$ to complete cDNA synthesis. Gene expression was analyzed using qPCR analysis with SYBR-Green PCR Master mix (Applied Biosystems; Thermo Fisher Scientific, Inc.) in a FAST Real-time PCR system with the following protocol: $95^{\circ} \mathrm{C} 30 \mathrm{sec}, 55^{\circ} \mathrm{C} 20 \mathrm{sec}, 72^{\circ} \mathrm{C} 20 \mathrm{sec}$ for 40 cycles with $\beta$-actin as an internal control. The reaction mixture $(20 \mu \mathrm{l})$ included: SYBR-Green $10 \mu \mathrm{l}$, cDNA $1 \mu \mathrm{l}$, forward prime $1 \mu \mathrm{l}$, reverse prime $1 \mu \mathrm{l}$, and DEPC water $7 \mu \mathrm{l}$. The following specific primers were designed to assess expression levels: HPSE, forward 5'-GCAGATGGCCCATACCTTCA-3' and reverse 5'-CACCTGGCTGCTCCCC-3'; HSPG, forward 5'-AAACGG ACAGAAGTCCTAGCAG-3' and reverse 5'-CTCATGCGA TACACCAACAGC-3'); FGF2, forward 5'-ATGGCTCCC TTAGCCGAAGT-3' and reverse 5'-AGGAAATGCGAACCC ACCTG-3'; and $\beta$-actin, forward 5'-CCGTTGCCCTGAGGC TCTTT-3' and reverse 5'-ACTGTGTTGGCATACAGGTCT T-3'. The $\Delta \Delta$ Cq value was calculated for each sample (19), and expression levels were expressed as $2^{-\Delta \Delta \mathrm{Cq}}$.

Western blot analysis. Proteins from the osteoblasts were lysed with RIPA buffer containing $300 \mathrm{mM} \mathrm{NaCl}, 50 \mathrm{mM}$ Tris- $\mathrm{HCl}$ (pH 7.6), 0.5\% TritonX-100, 2 mM PMSF, $2 \mu \mathrm{g} / \mathrm{ml}$ aprotinin and $2 \mu \mathrm{g} / \mathrm{ml}$ leupeptin, and incubated at $4^{\circ} \mathrm{C}$ for $1 \mathrm{~h}$. The lysates were centrifuged at $13,600 \mathrm{x}$ g for $15 \mathrm{~min}$ at $4^{\circ} \mathrm{C}$. Protein concentration was examined by BCA kit (Beyotime Institute of Biotechnology, Haimen, China). The supernatants $(\sim 100 \mu \mathrm{g})$ were electrophoresed on $10 \%$ SDS-PAGE gels, and the separated proteins were transferred onto nitrocellulose membranes. These membranes were blocked in 5\% non-fat milk overnight at $4^{\circ} \mathrm{C}$ and incubated with primary antibodies against HPSE (cat. no. PR-1645; 1:200; Zhenjiang Hope Biotechnology Co., Ltd.), FGF2 (cat. no. PB0619; 1:200; Boster Biological Technology, Ltd., Wuhan, China) and $\beta$-actin (cat. no. 1854-s; 1:500; Hangzhou Huaan Biotechnology Co., Ltd.) overnight at $4^{\circ} \mathrm{C}$. Following washing with PBS containing 0.5\% Tween-20 (PBS-T), the membranes were incubated with horseradish peroxidase-conjugated secondary antibodies $(1: 2,000$, goat-anti-rabbit, cat. no. HA1001; 1:2,000, goat-anti-mouse, cat. no. HA1006; Shanghai Huabio Co., Ltd.) and enhanced chemiluminescence reagents at $37^{\circ} \mathrm{C}$ for $1 \mathrm{~h}$. The immunoblots were scanned using a GS- 800 densitometer, and protein bands were quantified using QuantityOne version 4.62 software (Bio-Rad Laboratories, Inc., Hercules, CA, USA).

Statistical analysis. All values are expressed as the mean \pm standard error of the mean, and compared using one-way analysis of variance followed by Bonferroni's post hoc test. All statistical analyses were performed using SPSS 17.0 software (SPSS, Inc., Chicago, IL, USA). P $<0.05$ was considered to indicate a statistically significant difference. Figures were constructed using GraphPad Prism 5.0 software (GraphPad Software, Inc., La Jolla, CA, USA).

\section{Results}

Effects of unfractionated heparin and rivaroxaban on osteoblast viability. Osteoblasts were incubated with 
A
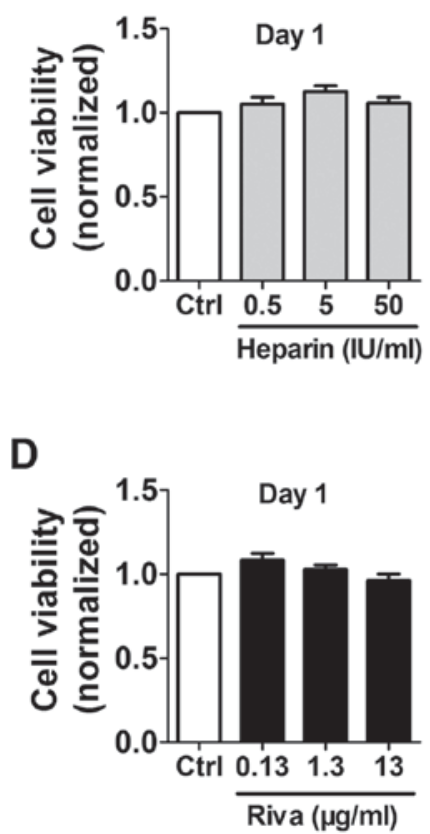

B

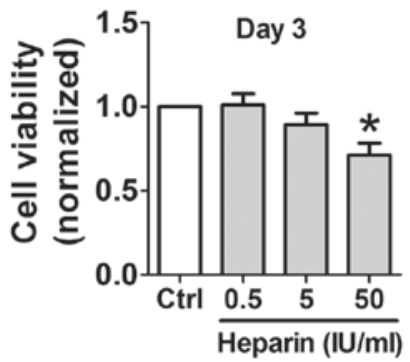

E

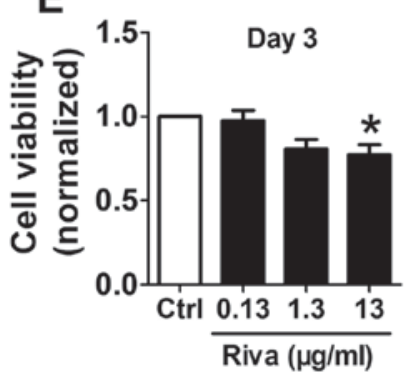

C
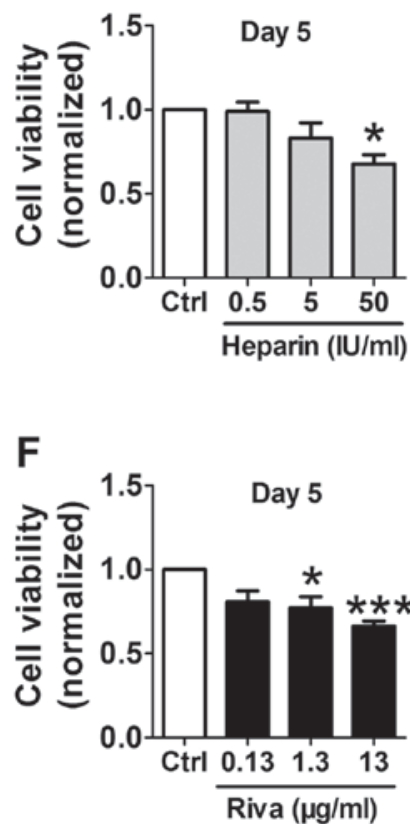

Figure 1. Effects of heparin and rivaroxaban on the viability of human osteoblasts. Human osteoblasts were cultured in the presence of various concentrations of heparin for (A and B) 3 or (C) 5 days, or rivaroxaban for (D) 1, (E) 3 or (F) 5 days, following which cell viability was assessed using MTT assays. Data are presented as the mean \pm standard error of the mean. ${ }^{*} \mathrm{P}<0.05$ and ${ }^{* * *} \mathrm{P}<0.001$, vs. $\mathrm{Ctrl}(\mathrm{n}=6)$. Riva, rivaroxaban; Ctrl, control.

unfractionated heparin $(0.5,5$ and $50 \mathrm{IU} / \mathrm{ml})$ or rivaroxaban $(0.13,1.3$ and $13 \mu \mathrm{g} / \mathrm{ml})$ for 1,3 and 5 days, and cell viability was determined using MTT assays. Although incubation with unfractionated heparin for 1 day did not significantly alter osteoblast viability (Fig. 1A), treatment for 3 and 5 days with $50 \mathrm{IU} / \mathrm{ml}$ unfractionated heparin significantly reduced cell viability, however lower doses had no significant effect (Fig. 1B and C). Rivaroxaban treatment for 1 day did not affect cell viability (Fig. 1D). Cell viability was significantly reduced by incubation with $13 \mu \mathrm{g} / \mathrm{ml}$ rivaroxaban for 3 and 5 days, and by treatment with $1.3 \mu \mathrm{g} / \mathrm{ml}$ for 5 days (Fig. 1E and F). Based on these findings, the osteoblasts were treated with $50 \mathrm{IU} / \mathrm{ml}$ unfractionated heparin and $13 \mu \mathrm{g} / \mathrm{ml}$ rivaroxaban for 3 days in the subsequent experiments.

Effects of unfractionated heparin and rivaroxaban on expression levels of HPSE, HSPG and FGF2. Treatment of osteoblasts with unfractionated heparin significantly reduced the mRNA level of HPSE and significantly increased the mRNA level of HSPG, compared with levels in the control cells $(\mathrm{P}<0.05$; Fig. $2 \mathrm{~A}$ and $\mathrm{B})$. By contrast, rivaroxaban did not significantly alter the mRNA levels of HPSE or HSPG. Treatment with unfractionated heparin or rivaroxaban significantly reduced the mRNA level of FGF2 (Fig. 2C). Consistent with the results of RT-qPCR analysis, western blot analysis of the protein expression of HPSE showed that the protein level of HPSE was downregulated by unfractionated heparin, but not by rivaroxaban (Fig. 2D). Incubation of the osteoblasts with either unfractionated heparin or rivaroxaban significantly reduced the protein levels of FGF2, with lower mRNA and protein levels of FGF2 in the rivaroxaban-treated cells, compared with the unfractionated heparin-treated cells (Fig. 2E).
Overexpression of HPSE or FGF2 increases osteoblast viability. The transfection of cells with plasmids encoding HPSE (Fig. 3A-C) markedly enhanced the expression mRNA and protein levels of FGF2, compared with the control and p-EGFP-N1-transfected cells. The assays of cell viability showed that the inhibitory effect of unfractionated heparin was overcome in HPSE-overexpressing cells (Fig. 3D). The transfection of cells with plasmids encoding FGF2 (Fig. 4A-C) markedly enhanced the expression levels of their respective mRNA and protein, and the inhibitory effects of unfractionated heparin or rivaroxaban were overcome in FGF2-overexpressing cells (Fig. 4D). These findings indicated that the overexpression of HPSE or FGF2 markedly reversed the adverse effects of unfractionated heparin or rivaroxaban on osteoblasts.

\section{Discussion}

The results of the present study demonstrated that the incubation of human osteoblasts with unfractionated heparin or rivaroxaban for 3 days inhibited the growth of the osteoblasts by downregulating the expression of HPSE and/or FGF2. The overexpression of HPSE and FGF2 overcame the adverse effects of unfractionated heparin and rivaroxaban. In our previous study, it was found that treatment with unfractionated heparin and rivaroxaban for 4 weeks had negative effects on bone microstructure and function in adult rats (9). Therefore, the results of the present in vitro study suggested that the negative effects of long-term treatment with unfractionated heparin or rivaroxaban on bone health were due to their ability to inhibit the growth of osteoblasts.

The expression of HPSE and HSPG affect chondrogenic and osteogenic processes during endochondral bone 
A

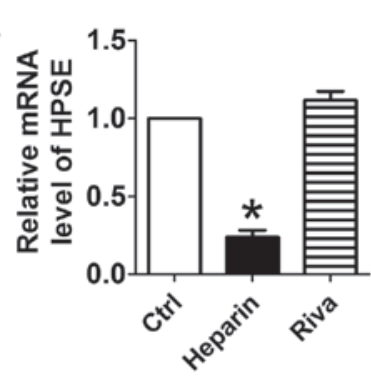

D
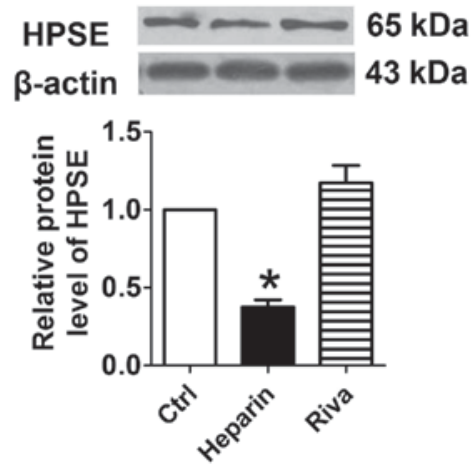

$65 \mathrm{kDa}$
B

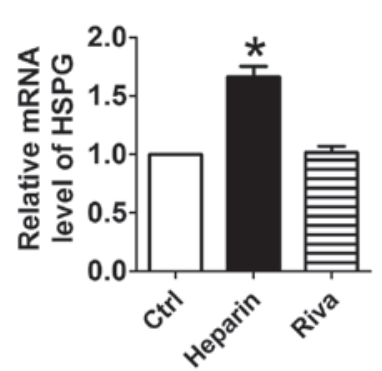

E
C

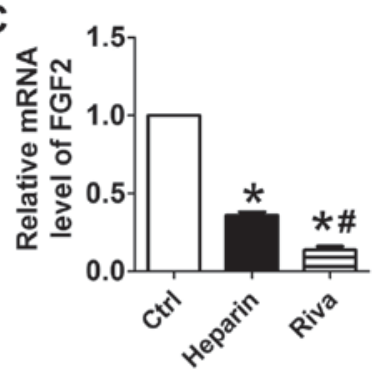

FGF2

$31 \mathrm{kDa}$

$\beta$-actin

$43 \mathrm{kDa}$

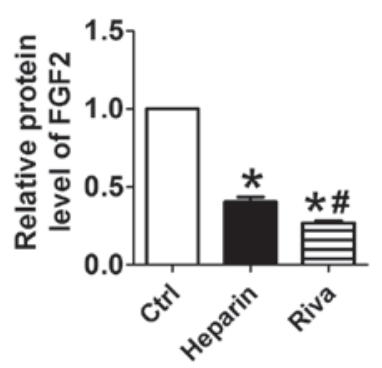

Figure 2. Effects of heparin and rivaroxaban on the mRNA expression of HPSE, HSPG and FGF2. Relative expression of (A) HPSE, (B) HSPG and (C) FGF2. ${ }^{*} \mathrm{P}<0.05$, vs. Ctrl; ${ }^{*} \mathrm{P}<0.05$, vs. heparin $(\mathrm{n}=5)$. Representative western blots of the expression of (D) HPSE and (E) FGF2, and the relative expression of each compared with $\beta$-actin. Data are presented as the mean \pm standard error of the mean, ${ }^{*} \mathrm{P}<0.05$, vs. control; ${ }^{*} \mathrm{P}<0.05$, vs. heparin (n=3). HPSE, heparanase; HSPG, heparan sulfate proteoglycan; FGF, fibroblast growth factor; Riva, rivaroxaban; Ctrl, control.

A

C

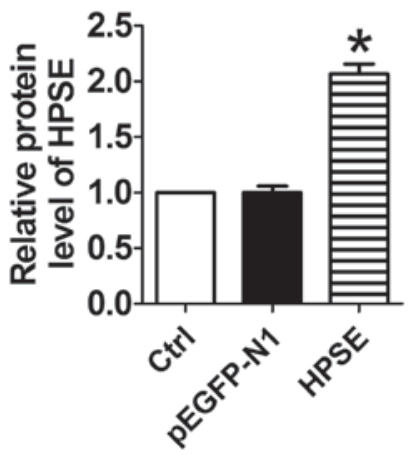

B

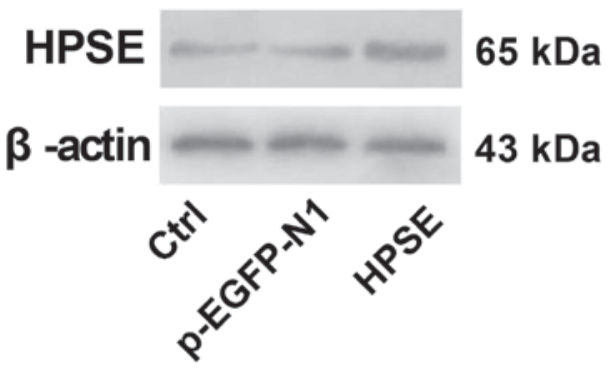

D

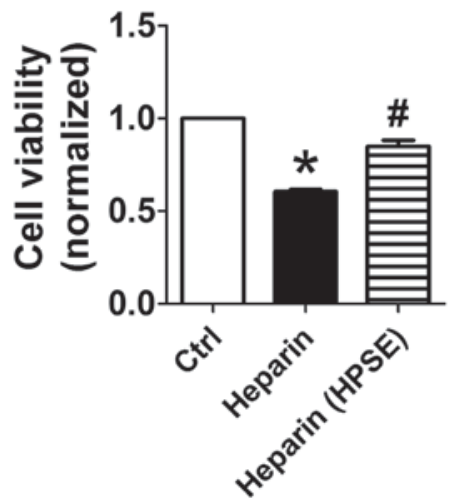

Figure 3. Overexpression of HPSE increases osteoblast viability. Transfection efficiency of plasmid encoding HPSE, determined using (A) reverse transcription-quantitative polymerase chain reaction analysis and (B) western blot analysis. (C) Relative expression of HPSE compared with $\beta$-actin. "P<0.05, vs. control, ${ }^{\prime} \mathrm{P}<0.05$, vs. heparin ( $\mathrm{n}=3$ ). (D) Viability of cells overexpressing HPSE. Data are presented as the mean \pm standard error of the mean. ${ }^{*} \mathrm{P}<0.05$, vs. control; ${ }^{\#} \mathrm{P}<0.05$, vs. heparin ( $\left.\mathrm{n}=5\right)$. HPSE, heparanase; $\mathrm{Ctrl}$, control.

formation $(20,21)$. The present study showed that unfractionated heparin significantly reduced the expression of HPSE and increased the expression of HSPG, however, these effects were not observed with rivaroxaban. FGF signals are important 
A
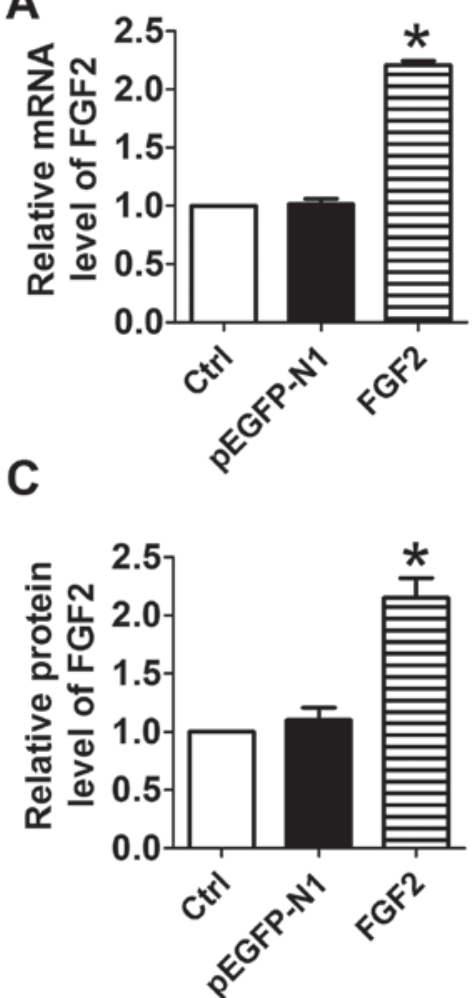

B
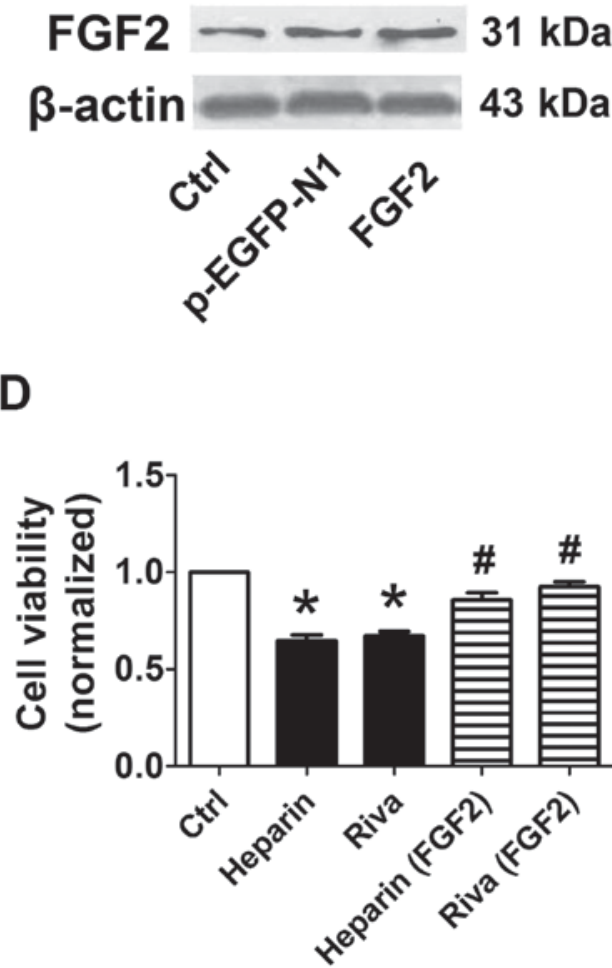

Figure 4. Overexpression of FGF2 increases osteoblast viability. Assessment of the transfection efficiency of a plasmid encoding FGF2 using (A) reverse transcription-quantitative polymerase chain reaction and (B) western blot analysis. (C) Relative expression of FGF2 compared with $\beta$-actin. * $\mathrm{P}<0.05$, vs. control; ${ }^{\#} \mathrm{P}<0.05$, vs. heparin ( $\left.\mathrm{n}=3\right)$. (D) Viability of cells overexpressing FGF2. Data are presented as the mean \pm standard error of the mean. "P<0.05, vs. Ctrl; ${ }^{~} \mathrm{P}<0.05$, vs. heparin or Riva ( $\mathrm{n}=5)$. FGF, fibroblast growth factor; Riva, rivaroxaban; Ctrl, control.

in bone formation and metabolism $(22,23)$. A previous study showed that bone mass and bone formation were markedly reduced in basic FGF2-knockout mice (24), whereas the overexpression of FGF2 by the osteoblastic lineage of transgenic mice resulted in increased bone mass (25). In the present study, unfractionated heparin and rivaroxaban did not affect the expression of FGF2 or other members of the FGF family, including FGF1 and FGF18 (data not shown), however, the contribution of other FGF members cannot be excluded.

Rivaroxaban treatment reduces the expression of the bone marker, osteocalcin, the major osteoblast factor, runt-related transcription factor-2, and osteogenic bone morphogenic protein-2, resulting in a negative effect on osteoblast function (17). Although the previous study found that treatment with 1.3 and $13 \mu \mathrm{g} / \mathrm{ml}$ rivaroxaban for 3 days did not have an adverse effect on osteoblast viability, it also showed that treatment with lower concentrations of rivaroxaban $(0.013$ and $0.13 \mu \mathrm{g} / \mathrm{ml}$ ) increased osteoblast viability by 15 and $10 \%$, respectively. By contrast, the present study found that treatment with $13 \mu \mathrm{g} / \mathrm{ml}$ rivaroxaban for 3 days markedly reduced cell viability. Therefore, further investigations are required to determine the reasons for this discrepancy, and the reasons why treatment with 1.3 and $13 \mu \mathrm{g} / \mathrm{ml}$ rivaroxaban for 5 days reduced osteoblast viability.

In our previous study, it was found that unfractionated heparin had a more marked adverse effect on bone microstructure and function, compared with rivaroxaban (9). The present study showed that rivaroxaban inhibited the expression of
FGF2, whereas unfractionated heparin repressed the expression of HPSE and FGF2. These findings may partly explain previous in vivo differences observed between these two drugs.

The present study had two limitations, one of which was its in vitro design. In vivo investigations in animals are required to confirm that unfractionated heparin and rivaroxaban regulate the expression of HPSE and FGF2 in osteoblasts. In addition, further investigations are required to examine the potential association between HPSE and FGF2.

In conclusion, the present study showed that treatment of osteoblasts with anticoagulants altered the expression of HPSE and FGF2. These findings may provide novel information regarding the side effects of unfractionated heparin and rivaroxaban in clinical practice.

\section{Acknowledgements}

This study was supported by a Research Grant from the Education Department of Heilongjiang Province of China (grant no. 12541443).

\section{References}

1. Mazziotti G, Canalis E and Giustina A: Drug-induced osteoporosis: Mechanisms and clinical implications. Am J Med 123: 877-884, 2010.

2. Panday K, Gona A and Humphrey MB: Medication-induced osteoporosis: Screening and treatment strategies. Ther Adv Musculoskelet Dis 6: 185-202, 2014. 
3. Bilen $\mathrm{O}$ and Teruya J: Complications of anticoagulation. Dis Mon 58: 440-447, 2012.

4. Rajgopal R, Bear M, Butcher MK and Shaughnessy SG: The effects of heparin and low molecular weight heparins on bone. Thromb Res 122: 293-298, 2008.

5. Duggan ST, Scott LJ and Plosker GL: Rivaroxaban: A review of its use for the prevention of venous thromboembolism after total hip or knee replacement surgery. Drugs 69: 1829-1851, 2009.

6. Klüter T, Weuster M, Brüggemann S, Menzdorf L, Fitschen-Oestern S, Steubesand N, Acil Y, Pufe T, Varoga D, Seekamp A and Lippross S: Rivaroxaban does not impair fracture healing in a rat femur fracture model: An experimental study. BMC Musculoskelet Disord 16: 79, 2015.

7. Somjen D, Katzburg S, Gigi R, Dolkart O, Sharon O, Salai M and Stern N: Rivaroxaban, a direct inhibitor of the coagulation factor $\mathrm{Xa}$ interferes with hormonal-induced physiological modulations in human female osteoblastic cell line SaSO2. J Steroid Biochem Mol Biol 135: 67-70, 2013.

8. Gigi R, Salai M, Dolkart O, Chechik O, Katzburg S, Stern N and Somjen D: The effects of direct factor Xa inhibitor (Rivaroxaban) on the human osteoblastic cell line SaOS2. Connect Tissue Res 53: 446-450, 2012.

9. Xia J, Zhang Z, Wang J, Zu J, Wang N and Wang D: Comparison of the effects of heparin and the direct factor Xa inhibitor, rivaroxaban, on bone microstructure and metabolism in adult rats. Connect Tissue Res 56: 477-482, 2015.

10. Saijo M, Kitazawa R, Nakajima M, Kurosaka M, Maeda S and Kitazawa S: Heparanase mRNA expression during fracture repair in mice. Histochem Cell Biol 120: 493-503, 2003

11. Kram V, Zcharia E, Yacoby-Zeevi O, Metzger S, Chajek-Shaul T, Gabet Y, Müller R, Vlodavsky I and Bab I: Heparanase is expressed in osteoblastic cells and stimulates bone formation and bone mass. J Cell Physiol 207: 784-792, 2006.

12. Smith PN, Freeman C, Yu D, Chen M, Gatenby PA, Parish CR and Li RW: Heparanase in primary human osteoblasts. J Orthop Res 28: 1315-1322, 2010

13. Ornitz DM and Marie PJ: Fibroblast growth factor signaling in skeletal development and disease. Genes Dev 29: 1463-1486, 2015.

14. Takei Y, Minamizaki T and Yoshiko Y: Functional diversity of fibroblast growth factors in bone formation. Int J Endocrinol 2015: 729352, 2015.
15. Hurley MM, Marie PJ and Florkiewics RZ: Fibroblast Growth Factor and Fibroblast Growth Factor Receptor Families. In: Principles of Bone Biology. Bilezikian JP, Raisz LG and Rodan G (eds). Academic Press, San Diego, CA, pp627-645, 2002.

16. Debiais F, Hott M, Graulet AM and Marie PJ: The effects of fibroblast growth factor-2 on human neonatal calvaria osteoblastic cells are differentiation stage specific. J Bone Miner Res 13: 645-654, 1998.

17. Solayar GN, Walsh PM and Mulhall KJ: The effect of a new direct factor Xa inhibitor on human osteoblasts: An in-vitro study comparing the effect of rivaroxaban with enoxaparin. BMC Musculoskelet Disord 12: 247, 2011.

18. Ramani VC, Yang Y, Ren Y, Nan L and Sanderson RD: Heparanase plays a dual role in driving hepatocyte growth factor (HGF) signaling by enhancing HGF expression and activity. J Biol Chem 286: 6490-6499, 2011.

19. Livak KJ and Schmittgen TD: Analysis of relative gene expression data using real-time quantitative PCR and the 2(-Delta Delta C(T)) method. Methods 25: 402-408, 2001.

20. Brown AJ, Alicknavitch M, D'Souza SS, Daikoku T, Kirn-Safran CB, Marchetti D, Carson DD and Farach-Carson MC: Heparanase expression and activity influences chondrogenic and osteogenic processes during endochondral bone formation. Bone 43: 689-699, 2008

21. Han Q, Liu F and Zhou Y: Increased expression of heparanase in osteogenic differentiation of rat marrow stromal cells. Exp Ther Med 5: 1697-1700, 2013.

22. Fei Y, Gronowicz G and Hurley MM: Fibroblast growth factor-2, bone homeostasis and fracture repair. Curr Pharm Des 19: 3354-3363, 2013.

23. Marie PJ, Miraoui $\mathrm{H}$ and Sévère N: FGF/FGFR signaling in bone formation: Progress and perspectives. Growth Factors 30: 117-123, 2012.

24. Montero A, Okada Y, Tomita M,Ito M, Tsurukami H, Nakamura T, Doetschman T, Coffin JD and Hurley MM: Disruption of the fibroblast growth factor-2 gene results in decreased bone mass and bone formation. J Clin Invest 105: 1085-1093, 2000.

25. Xiao L, Ueno D, Catros S, Homer-Bouthiette C, Charles L, Kuhn L and Hurley MM: Fibroblast growth factor-2 isoform (low molecular weight $/ 18 \mathrm{kDa}$ ) overexpression in preosteoblast cells promotes bone regeneration in critical size calvarial defects in male mice. Endocrinology 155: 965-974, 2014. 